\title{
Molecular genetic identification of symbiotic dinoflagellates (zooxanthellae)
}

\author{
Rob Rowan, Dennis A. Powers \\ Department of Biological Sciences, Stanford University, The Hopkins Marine Station, Pacific Grove, California 93950, USA
}

\begin{abstract}
Zooxanthellae are phototrophic dinoflagellates that occur as endosymbionts in many marine invertebrates. Because traditional biological methods have not provided useful schemes for zooxanthella identification and classification, the natural history of zooxanthella symbioses is poorly known. We have applied molecular genetic methods to zooxanthella taxonomy. Small ribosomal subunit RNA (ssRNA) genes can be rapidly obtained from small amounts of symbiotic (non-cultured) algae by gene amplification using the polymerase chain reaction. Different Symbiodinium-like zooxanthellae are then identified by digesting the amplified DNA with restriction enzymes. A sample of 16 cnidarian host species yielded 6 distinct Symbiodinium ssRNA genes: different Hawaiian corals harbored different algae, but different individuals of the same coral species harbored indistinguishable algae. The corals Pocillopora damicornis and P. meandrina appear to contain a mixture of 2 zooxanthella ssRNA genes; other hosts exhibited a single zooxanthella genotype. The same algal genotype occurs in taxonomically dissimilar hosts.
\end{abstract}

\section{INTRODUCTION}

Zooxanthellae are phototrophic dinoflagellates that occur as endosymbionts in many marine invertebrates (McLaughlin \& Zahl 1966; reviewed by Trench 1987). Primary production by these symbioses, especially the reef-building corals, is essential to the life and growth of tropical reef communities (Goreau \& Goreau 1959, Muscatine \& Porter 1977). Most zooxanthellae are not obviously different from each other. Many, including the symbionts from hard and soft corals, anemones and giant clams, were originally (Kevin et al. 1969, Taylor 1974) believed to be the single pandemic species Symbiodinium microadriaticum Freudenthal. More detailed analyses of zooxanthella cultures subsequently refuted this conclusion (Blank \& Trench 1985, Blank et al. 1988, Blank \& Huss 1989; reviewed by Trench 1987) and led to the description of 3 additional Symbiodinium species (Trench \& Blank 1987). Because Symbiodinium-like algae undoubtedly represent a collection of many cryptic taxa, these algae in nature can only be referred to as Symbiodinium sp. (Blank \& Trench 1986).

Taxonomic studies of the Symbiodinium-like zooxanthellae have been hindered by their problematic biology: a paucity of informative morphology, especially in the vegetative (symbiotic) state (Freudenthal 1962, Taylor 1969); the possible complications of hostassociated phenotypic plasticity, restricting definitive studies to the fraction of zooxanthellae that can be cultured in vitro (Schoenberg \& Trench 1980a, b); the absence of sexual reproduction, precluding genetic investigátions. Whereas many studies have demonstrated biological diversity, they have not provided useful schemes for zooxanthella identification and classification. The poor status of zooxanthella taxonomy in turn limits the study of the ecology and evolution of zooxanthella symbioses.

Molecular genetic methods can obviate many of the difficulties in zooxanthella taxonomy. DNA sequences are excellent phylogenetic data (reviewed by Hillis 1987. Nei 1987) that are especially useful for identifying and classifying morphologically depauperate or phenotypically plastic organisms. Using zooxanthellae cultured in vitro, we recently discovered that nuclearencoded, small ribosomal subunit RNA (ssRNA) sequences are useful in Symbiodinium taxonomy (Rowan \& Powers 1991a). We have now developed methods by which these data may be obtained from natural populations. The Polymerase Chain Reaction (PCR; Saiki et al. 1988, Innis et al. 1990) is used to specifically amplify zooxanthella ssRNA genes from small samples, and different zooxanthellae are rapidly and precisely identified by digesting the amplified DNA with restriction enzymes. Phylogenetic relationships among the zooxanthellae are inferred from ssRNA gene sequences (Rowan \& Powers 1991b). 


\section{METHODS AND MATERIALS}

All steps were at room temperature except as indicated.

Zooxanthella isolation. Zooxanthellae were obtained from anemones maintained in laboratory culture (Aiptasia pulchella from Oahu, Hawaii) provided by G. Muller-Parker (Shannon Pt. Marine Center, Western Washington University), and from other hosts that were collected from nature: the anemones Anthopleura xanthogrammica and A. elegantissima (Pacific Grove, California); the gorgonian Plexaura A (Bahamas); the zoanthids Zoanthus pacificus, Palythoa tuberculosa and $P$. vestitus (Oahu, Hawaii) and $Z$. sociatus (St. Croix, US Virgin Islands); the corals Astrangia danae (Woods Hole, Massachusetts) and Pavona varians, Pavona duerdeni, Montipora verrucosa, M. patula, Fungia (Pleuractis) scutaria, Pocillopora damicornis and Pocillopora meandrina (Oahu, Hawaii); the jellyfishes Cassiopeia xamachana and C. frondosa (St. Croix, US Virgin Islands). Zooxanthellae were isolated from these animals as follows: Hosts (or parts thereof) were homogenized in 5 to $10 \mathrm{ml}$ of 'Zooxanthella Isolation Buffer' (ZB): $0.4 \mathrm{M} \mathrm{NaCl}_{4} 40 \mathrm{mM} \mathrm{MgSO}$; $10 \mathrm{mM}$ EDTA; $20 \mathrm{mM}$ Tris-HCl, pH 7.6; $8 \mathrm{mM}$ dithiothreitol; $0.05 \% \quad(\mathrm{v} / \mathrm{v})$ Tween-20 (polyoxyethylene-sorbitan monolaurate; Sigma Chemical Co.). Zooxanthella-containing tissues from anemones ( 3 to 6 Anthopleura tentacles; whole Aiptasia), zoanthids (the distal onethird of individual polyps) and gorgonians (outer tissue from a 1 to $2 \mathrm{~cm}$ piece), and jellyfish (ca 1 to $2 \mathrm{~cm}^{2}$ of tissue from the bell margin) were homogenized using a dounce-type homogenizer. These homogenates were filtered through $100 \mu \mathrm{m}$ nylon mesh (Nitex) to remove larger pieces of animal tissue. Coral tissue was stripped from skeletons and homogenized by repeatedly 'blasting' small pieces (ca 5 to $20 \mathrm{~cm}^{2}$ surface area) with ZB from a syringe. Zooxanthellae were recovered from tissue homogenate by centrifugation at ca $50 \times g$ in a swinging-bucket rotor, and the algal cell pellets were washed in 5 to $10 \mathrm{ml}$ of fresh ZB and re-pelleted.

Cultured zooxanthellae provided by R. K. Trench (Department of Biological Sciences, University of California at Santa Barbara) included Symbiodinium microadriaticum (from Cassiopeia xamachana, Jamaica), S. pilosum (from Zoanthus sociatus, Jamaica), and Symbiodinium \#8 (from Aiptasia pulchella, Oahu, Hawaii).

Zooxanthella DNA. Zooxanthella cells were washed a second time in $1 \mathrm{ml}$ 'DNA Isolation Buffer' (DNAB: $0.4 \mathrm{M} \mathrm{NaCl}_{;} 50 \mathrm{mM}$ EDTA, $\mathrm{pH} 8.0$ ) in a microcentrifuge tube, and then resuspended in $0.4 \mathrm{ml}$ DNAB with sodium dodecyl sulfate (SDS) added to a final concentration of $1 \%(\mathrm{v} / \mathrm{v})$ and heated to $65^{\circ} \mathrm{C}$ for 30 to $60 \mathrm{~min}$. The samples were then incubated at 37 to $45^{\circ} \mathrm{C}$ in the presence of Proteinase $\mathrm{K}$ (BoehringerMannheim Biochemicals; $0.5 \mathrm{mg} \mathrm{ml}^{-1}$ final concentration) for at least $6 \mathrm{~h}$. These lysates can be stored indefinitely at $-20^{\circ} \mathrm{C}$ and are stable for at least $2 \mathrm{wk}$ at room temperature. Nucleic acid was purified from the lysates as follows: the concentration of $\mathrm{NaCl}$ was increased to $0.8 \mathrm{M}, 20 \mu \mathrm{g}$ of Escherichia coli tRNA (Boehringer-Mannheim Biochemicals) was added as carrier, cetyltrimethylammonium bromide (CTAB; Aldrich Chemical Company) was added to a final concentration of $1 \%(\mathrm{w} / \mathrm{v})$, and the lysates were heated to $65^{\circ} \mathrm{C}$ for $30 \mathrm{~min}$. The lysates were then chloroformextracted once, phenol-extracted twice, and the nucleic acids were precipitated with ethanol at $-20^{\circ} \mathrm{C}$. Nucleic acid precipitates were resuspended in $100 \mu \mathrm{l}$ of $0.3 \mathrm{M}$ sodium acetate, precipitated again with ethanol, and then resuspended in $50 \mu \mathrm{l}$ of water and stored at $-20{ }^{\circ} \mathrm{C}$.

Zooxanthella genes could generally be PCRamplified from these preparations, but some samples required more purification: samples were adjusted to $0.8 \mathrm{M} \mathrm{NaCl} ; 50 \mathrm{mM}$ EDTA, pH 8.0; $0.1 \%$ SDS; $1 \%$ $\mathrm{CTAB}$, heated to $65^{\circ} \mathrm{C}$ for $30 \mathrm{~min}$, and extracted once with chloroform and precipitated twice with ethanol as above. Other samples, e.g. zooxanthellae from Porites corals and from some gorgonians (R.R. unpubl.), remained brown-colored through all organic extractions and ethanol precipitations. DNA could only be PCR-amplified if this brown color was first removed by ultrafiltration (Millepore Ultrafree-MC centrifugal filtration units) with DNAB prior to ethanol precipitation. Samples of DNA from cultured zooxanthellae have been described (Rowan \& Powers 1991a).

Animal DNA. Naturally aposymbiotic Astrangia danae were collected at Woods Hole, Massachusetts, and polyps were plucked from a colony that had been narcotized with $\mathrm{MgCl}_{2}$. A culture of aposymbiotic Aptasia pallida, originally from Bermuda, was provided by G. Muller-Parker. Psammogorgia arbuscula was collected in Monterey Bay, California. Approximately 0.1 $\mathrm{ml}$ of animal tissue was rinsed in $1 \mathrm{ml}$ of $\mathrm{DNAB}$, and then ground in $0.8 \mathrm{ml}$ of DNAB. The tissues were lysed with $1 \%$ SDS and DNA was purified from the lysates as for zooxanthellae (above).

DNA amplification. Small subunit ribosomal RNA (ssRNA) genes were amplified from total nucleic acid samples using either 'universal eukaryotic' (Medlin et al. 1988, Rowan \& Powers 1991a, Sogin 1990) or 'zooxanthella-specific' PCR primers. The universal primers ss5 (5'-GGTTGATCCTGCCAGTAGTCATATGCTTG$\left.3^{\prime}\right)$ and ss3 (5'-GATCCTTCCGCAGGTTCACCTACGGAAACC-3') have been described (Rowan \& Powers 1991a). The design of zooxanthella-specific primers ss5Z (an equimolar mixture of the oligonucleotides 5'GCAGTTATAATTTATTTGATGGTCACTGCTAC - $3^{\prime}$ 
and 5'-GCAGTTATAGTTTATTTGATGGTTGCTGCTAC-3') and ss3Z (5'-AGCACTGCGTCAGTCCGAATAATTCACCGG-3') is described below ('Results'). DNA amplifications were performed using the GeneAmp PCR kit and the DNA Thermal Cycler (Perkin Elmer-Cetus) according to the manufacturers instructions. Amplifications (volume $=100 \mu \mathrm{l}$ ) contained $4 \mu$ of total nucleic acid (above) and consisted of 30 cycles of the following thermal profile: $1 \mathrm{~min}$ at $94^{\circ} \mathrm{C} ; 2 \mathrm{~min}$ at $55^{\circ} \mathrm{C} ; 3 \mathrm{~min}$ at $72^{\circ} \mathrm{C}$. Completed amplifications were extracted once with chloroform and the amplified DNA was precipitated with ethanol at $-20^{\circ} \mathrm{C}$. The precipitates were resuspended in water and stored at $-20^{\circ} \mathrm{C}$.

Characterization of amplified DNA. Between 5 and $10 \%$ of each amplification reaction was analyzed directly by electrophoresis in $1 \%$ SeaKem LE agarose (FMC BioProducts) in order to estimate yield. An appropriate amount was then digested with one of several restriction endonucleases. One amplification typically provided enough product for 3 to 5 digests. Restriction fragments were analyzed by electrophoresis in $3.5 \%$ Nusieve $/ 1 \%$ SeaKem LE agarose (FMC BioProducts).

Amplified ssRNA genes from Astrangia danae, Aiptasia pallida and Psammogorgia arbuscula were purified by electrophoresis in $1 \%$ SeaPlaque agarose (FMC BioProducts) and cloned as blunt-ended fragments into bacteriophage M13mp18 (Yanisch-Perron et al. 1985) for sequencing at either end. Single-stranded DNA prepared from recombinant bacteriophage was sequenced using a Sequinase Kit (US Biochemicals).

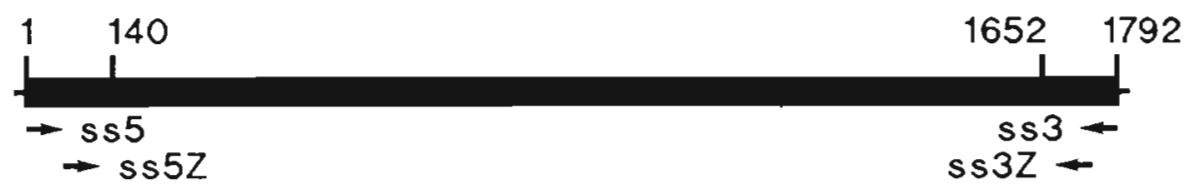

$\underline{1}$

(a) GGTGATCCTGCCAGTAGTCATATgCTTGTCTCAAAGATTAAGCCATGCATGTCTAAGTATAAGCACTAG

(b) - (c)

(c)

(d)

(e)

ss 5

$14 \underline{0}$

TACTGTGAAACTGCGAATGGCTCATTAAATCAGTTATCGTTTATTTGATTGTACCTTTA CTACTTGGA

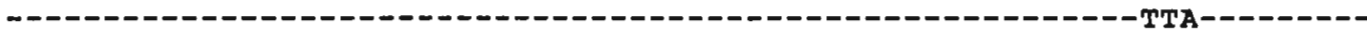

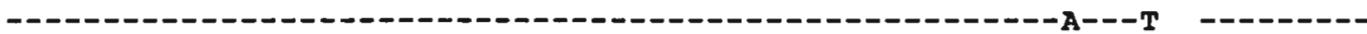

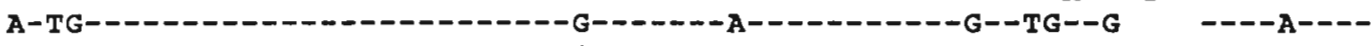

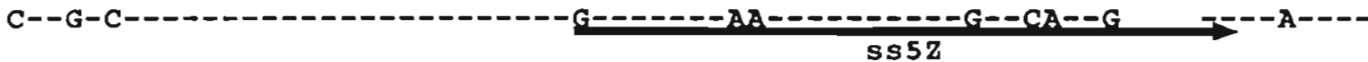

1652

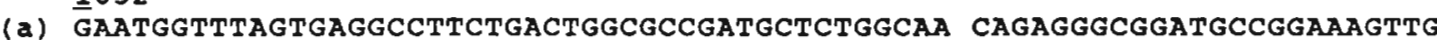

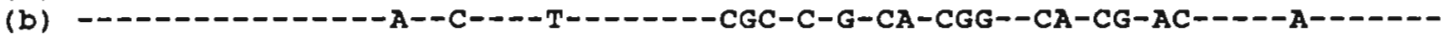

(c) --

(d) -- G--A-CCG--- ATAA---G-----A---A- -----A-CTTCTGGAC-TTGT-T-- $------T$

(e) $--G--A-C C G----A T T A---G-----A---A-----A-C T T C T G G A C-T T G C-T--$ $\mathbf{s 3 3 2}$

$179 \underline{2}$

GTCAAACTTGATCATTTAGAGGAAGTAAAATCGTAACAAGGTTTCCGTAGGTGAACCTGCGGAAGATC

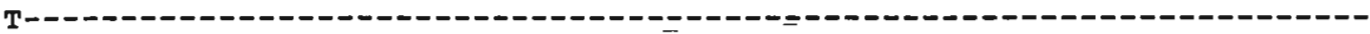

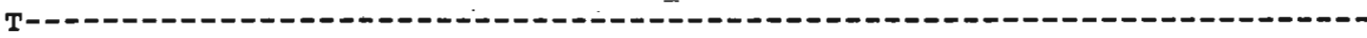

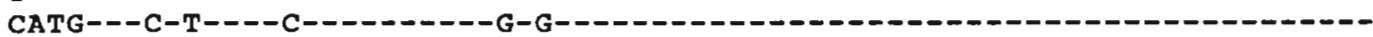

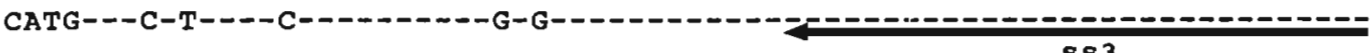

Fig. 1. PCR-amplification strategy for Symbiodinium ssRNA genes. The schematic diagram shows the location of universal eukaryotic primers (arrows) ss5 and ss3 at the 5' and 3 ' ends (respectively) of ssRNA-encoding DNA (heavy line), and also the location of the zooxanthella-specific primers ss5Z and ss3Z. The positions (nucleotides 1-140 and 1652-1792) of the following ssRNA sequences are indicated (nucleotide positions are numbered according to Symbiodinium ssRNA sequences (Rowan \& Powers 1991a). Sequences of the $5^{\prime}$ end (1-140) and 3' end (1652-1792) of ssRNA genes from (a) the coral Astrangia danae, (b) the anemone Aiptasia pallida, (c) the sea pen Psammogorgia arbuscula, (d) the zooxanthella Symbiodinium \#8, and (e) the zooxanthella Symbiodinium microadriaticum are shown in alignment. Dashes indicate identity to the Astrangia danae sequence, sequence differences are explicitly indicated, and blank spaces indicate apparent deletions. Positions in the zooxanthella sequences that correspond to PCR primers (ss5, ss5z, ss 3 and ss $3 Z$ ) are underlined with arrows, the arrowhead representing the $3^{\prime}$ end of the primer 


\section{RESULTS}

Highly conserved sequences at the $5^{\prime}$ and $3^{\prime}$ ends of ssRNA make it possible to amplify ssRNA-encoding DNA from the nuclear genome of any eukaryote with the same 'universal' PCR primers (Medlin et al. 1988. Sogin 1990; see Fig. 1). We previously used this method to obtain ssRNA sequences from zooxanthellae and other dinoflagellates that had been cultured in vitro (Rowan \& Powers 1991a). The PCR produces large amounts of DNA from very small samples (Saiki et al. 1988, Saiki 1990), and the zooxanthellae contained in even a small host should provide enough material for gene amplification. Preliminary observations, however, suggested that freshly isolated zooxanthellae are often contaminated with host DNA, making universal PCR primers inappropriate for routine analyses of natural isolates (see below). Therefore, 'zooxanthella-specific' PCR primers were designed by the following strategy.

Because the ssRNA molecule is a mosaic of variably conserved domains (Sogin et al. 1986, Sogin \& Gunderson 1987), and since zooxanthellae are more closely related to one another than to any of their animal hosts, there should be sites in the ssRNA molecule that are both conserved among zooxanthellae and different from the homologous host sequences. These provide priming sites for the specific amplification of zooxanthella DNA. Comparisons of nuclear-encoded ssRNA sequences from many taxa (Sogin et al. 1986, Dams et al. 1988) suggested that such sites occur near the universal priming sites that were used previously. These sites were more accurately located by sequencing the relevant DNA from 3 anthozoans and comparing these data to homologous zooxanthella sequences (Fig. 1). Noting that primer-template mismatch at the primer $3^{\prime}$ end should block the PCR (see Wu et al. 1989), the zooxanthella-specific primers ss5Z and ss3Z were designed from this comparison (see Fig. 1). The 2 zooxanthella sequences show 3 nucleotide substitutions within ss5Z, so an equimolar mixture of the corresponding 2 oligonucleotides was used as the primer.

The specific amplification of zooxanthella sSRNA genes is demonstrated in Fig. 2. Each panel shows PCR products obtained from (1) cultured Symbiodinium \#8 from Aiptasia pulchella, (2) aposymbiotic Astrangia danae, (3) aposymbiotic Aiptasia pallida, (4) zooxanthellae freshly isolated from Astrangia danae, and (5) zooxanthellae freshly isolated from Aptasia pulchella. The amplification of these templates with universal primers (to the left) and with zooxanthella-specific primers (to the right) is compared. PCRs with universal primers show that each sample contains amplifiable DNA, and the apparent size of the PCR products [1800 base pairs (bp)] is correct for ssRNA genes (Fig. 2A, left; predicted sizes of PCR products are obtained from

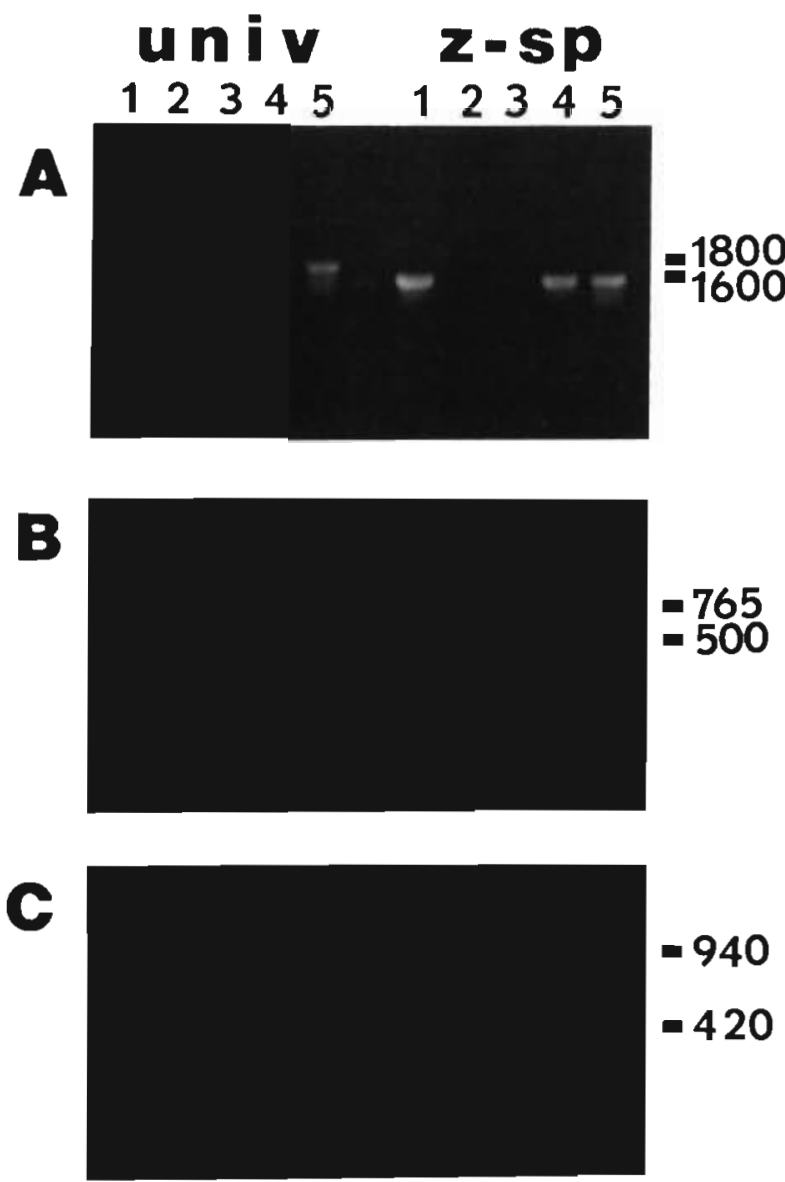

Sau3A

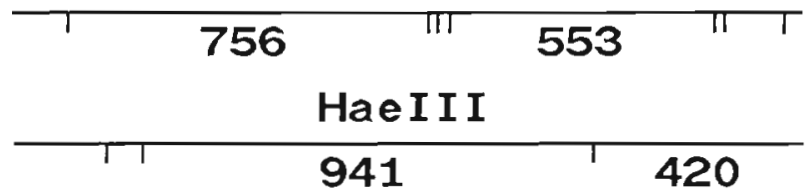

Fig. 2. Specific amplification of ssRNA genes from freshly isolated Symbiodinium samples. ssRNA genes were amplified using either universal PCR primers ss5 and ss3 (univ) or zooxanthella-specific PCR primers ss $5 Z$ and ss $3 Z$ ( $z$-sp) and genomic DNA from the following sources: (1) cultured Symbiodinium $\not 8^{2}$; (2) aposymbiotic Astrangia danae; (3) aposymbiotic Aiptasia pallida; (4) zooxanthellae freshly isolated from Astrangia danae; (5) zooxanthellae freshly isolated from Aiptasia pulchella. (A) Untreated PCR products separated by agarose gel electrophoresis, with their apparent sizes in base pairs (bp) indicated. (B) PCR products were digested with the restriction enzyme Sau $3 \mathrm{~A}$, and the DNA fragments were separated by agarose gel electrophoresis. Apparent sizes (in $b p$ ) of diagnostic restriction fragments are indicated. (C) PCR products digested with the restriction enzyme HaeIII, with apparent sizes of diagnostic fragments. Sau3A and HaeIII restriction maps of the Symbiodinium \#8 ssRNA gene (specifically, of the PCR product obtained using primers $5 s 5 Z$ and $s 53 Z$ ) as defined by the DNA sequence (Rowan \& Powers 1991a) are given below (restriction fragments seen in (B) and (C) are indicated) 
the numerical data in Fig. 1). Zooxanthella-specific primers yield PCR products only from zooxanthellacontaining samples (Fig. 2A, right), and their smaller apparent size (1600 bp) accords with these primers being internal to the universal primers (Fig. 1).

A restriction enzyme digestion of these PCR products differentiates zooxanthella ssRNA genes from animal ssRNA genes (Fig. 2B, C). On the left, comparing the amplified animal DNAs with the amplified zooxanthella DNAs suggests that freshly isolated zooxanthellae contain both Symbiodinium and animal ssRNA genes. Specifically, these samples (lanes 4 and 5) exhibit the restriction fragments that identify both cultured zooxanthellae (lane 1) and the aposymbiotic hosts (lanes 2 and 3). Washing freshly isolated zooxanthellae more extensively and treating them briefly with deoxyribonuclease prior to lysis yields DNA preparations that contain only Symbiodinium ssRNA genes (by the above criterion) in most instances (not shown). Thus, the 'host-like' PCR products identify surface contaminants and not part of the zooxanthella genome. Using zooxanthella-specific primers (Fig. 2B, C, right), 'host-like' PCR products are undetectable and the freshly isolated zooxanthellae appear identical to those from cultured Symbiodinium \#8. The apparent sizes of the zooxanthella-specific Sau3A and HaeIII restriction fragments agree with restriction maps of the Symbiodinium \#8 ssRNA gene (Fig. 2, bottom). Taken together, the data presented in Figs. $1 \& 2$ show that zooxanthella ssRNA genes can be rapidly obtained from small, easily prepared samples of field-collected material.

The ssRNA gene sequences of the cultured zooxanthellae Symbiodinium microadriaticum and Symbiodinium \#8 (Rowan \& Powers 1991a) differ by several restriction enzyme recognition sites. This observation

\section{4}
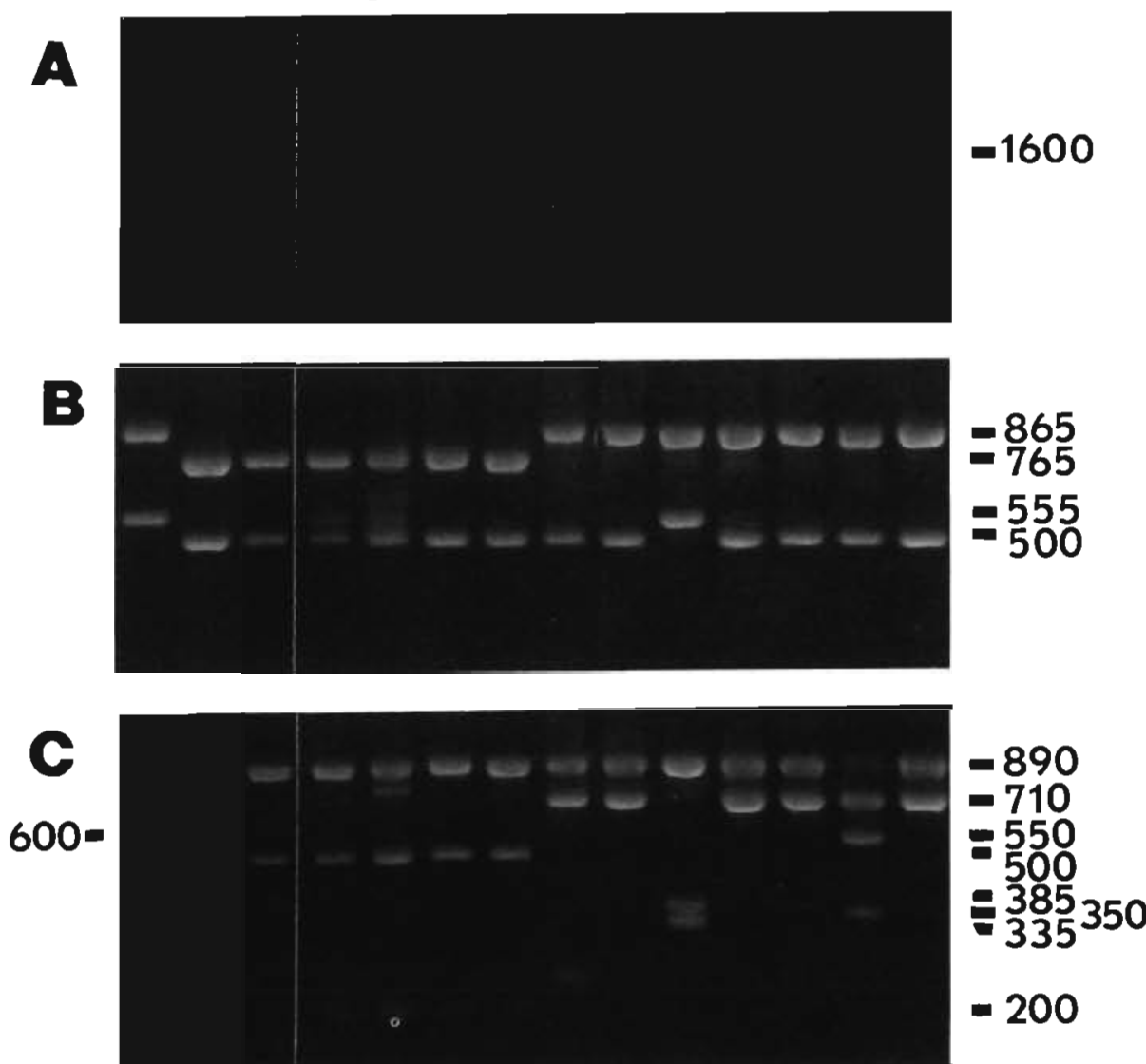

Fig. 3. Comparison of the zooxanthellae from different hosts using ssRNA gene RFLPs. ssRNA genes were amplified using zooxanthella-specific PCR primers $5 s 5 Z$ and $s s 3 Z$ from (1) cultured Symbiodinium microadriaticum (original host: Cassiopeia xamachana) and (2) cultured Symbiodinium \#8 (original host: Aiptasia pulchella), and from zooxanthellae that were freshly isolated from the following hosts: (3) Aiptasia pulchella; (4) Anthopleura elegantissima; (5) Anthopleura xanthogrammica; (6) Astrangia danae; (7) Plexaura $A_{i}$ (8) Zoanthus pacificus; (9) Palythoa tuberculosa; (10) Palythoa vestitus; (11) Pavona duerdeni; (12) Pavona varians; (13) Pocillopora damicornis; (14) Montipora verrucosa. (A) Untreated PCR-amplification products. (B) PCRamplification products digested with Sau3A. (C) PCR-amplification products digested with TaqI. Apparent sizes (in bp) of diagnostic restriction fragments are indicated. DNA fragments were separated by agarose gel electrophoresis 
indicated that different zooxanthellae could be identified by restriction fragment length polymorphisms (RFLPs) in PCR-amplified ssRNA genes. Exemplary data are presented in Fig. 3, which includes cultured $S$. microadriaticum and Symbiodinium \#8 (lanes 1 and 2) and 12 fresh zooxanthella isolates (lanes 3 to 14). Five different RFLPs (= different zooxanthella ssRNA genes) are detected using the restriction enzyme TaqI (Fig. 3C) and 4 of these are also detected with Sau3A (Fig. 3B). These RFLPs are confirmed by zooxanthella ssRNA gene sequences (Rowan \& Powers 1991a, b and unpubl.) or, in the case of algae from Palythoa vestitus (the relevant sequences have not been obtained from this isolatej, they are predicted by assuming a single nucleotide substitution in the consensus sequence. Minor bands that appear in some restriction enzyme digests have been ignored for the present (for example, Fig. 3C, lanes 4 and 5 are not scored as different). These fragments remain unexplained, but they are characteristic of the algae from some host species (not shown). By host, the 5 zooxanthella genotypes in Fig. 3 correspond to (I) Cassiopeia xamachana (cultured S. microadriaticum, lane 1); (II) Aiptasia pulchella (lanes 2 and 3), Anthopleura elegantissima (lane 4), Anthopleura xanthogrammica (lane 5), Astrangia danae (lane 6) and Plexaura A (lane 7); (III) Zoanthus pacificus (lane 8), Palythoa tuberculosa (lane 9), Pavona duerdeni (lane 11), Pavona varians (lane 12) and Montipora verrucosa (lane 14); (IV) Palythoa vestitus (lane 10); (V) Pocillopora damicornis (lane 13). With the possible exception of $P$. damicornis (see below), each of these hosts contains only 1 of the 5 zooxanthella genotypes.

In Fig. 3, the freshly isolated zooxanthellae from Aiptasia pulchella (lane 3) resemble algae that were cultured from this host (Symbiodinium \#8, lane 2). Cultured Symbiodinium microadriaticum (from the jellyfish Cassiopeia xamachana) and cultured S. pilosum (from Zoanthus sociatus) similarly resemble algae that were freshly isolated from their hosts of origin (Fig. 4). One specimen of Cassiopeia frondosa from St. Croix (Fig. 4, lane 3) harbored algae that do not resemble $S$.

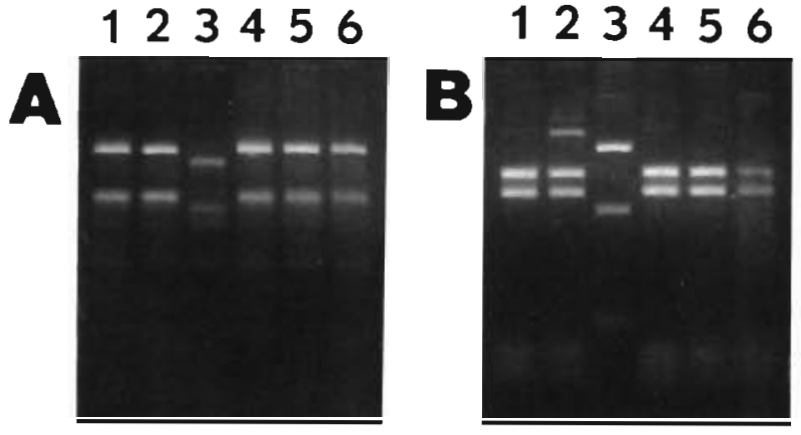

Fig. 4. Comparison of cultured and freshly isolated zooxanthellae using ssRNA RFLPs. ssRNA genes were amplified using zooxanthella-specific PCR primers ss $5 Z$ and ss $3 Z$ from the following: (1) cultured Symbiodinium microadriaticum (originally from Cassiopeia xamachana); (2) zooxanthellae freshly isolated from Cassiopeia xamachana; (3) zooxanthellae freshly isolated from Cassiopeia frondosa; (4) cultured Symbiodinium pilosum (originally from Zoanthus sociatus); (5 $\&$ b) zooxanthellae treshly isolated from 2 color morphs of Zoanthus sociatus. PCR products were digested with Sau3A (A) or with TaqI (B), and the fragments were separated by agarose gel electrophoresis

microadriaticum from $C$. xamachana, but that do resemble Symbiodinium \#8 (Fig. 3, refer to lanes 1 and 2). Elsewhere, by different criteria, C. xamachana and C. frondosa appear to contain identical algae (Trench \& Blank 1987).

Finding different zooxanthella genotypes raises the issue of host specificity. Of the limited fauna that has been sampled so far, this question is best addressed among the Hawaiian corals. These host species are unambiguously identifiable (Maragos 1977) and here various hosts have access to the same zooxanthella flora. Exemplary data are presented in Fig. 5. As for other corals that have been examined (not shown), the zooxanthella ssRNA genotype is host-specific for these 5 species. Montipora patula zooxanthellae exhibit an RFLP that is not seen in Fig. 2, 3 or 4, making a total of 6 detectable zooxanthella genotypes in 16 host species. Note that Pocillopora meandrina may harbor 2 zooxanthella genotypes. The zooxanthella RFLP from $P$.

\section{$\begin{array}{lllllllllllllllllllllllll}1 & 2 & 3 & 4 & 5 & 6 & 7 & 8 & 9 & 10 & 11 & 12 & 13 & 14 & 15 & 16 & 17 & 18 & 19 & 20 & 21 & 22 & 23 & 24 & 25\end{array}$}

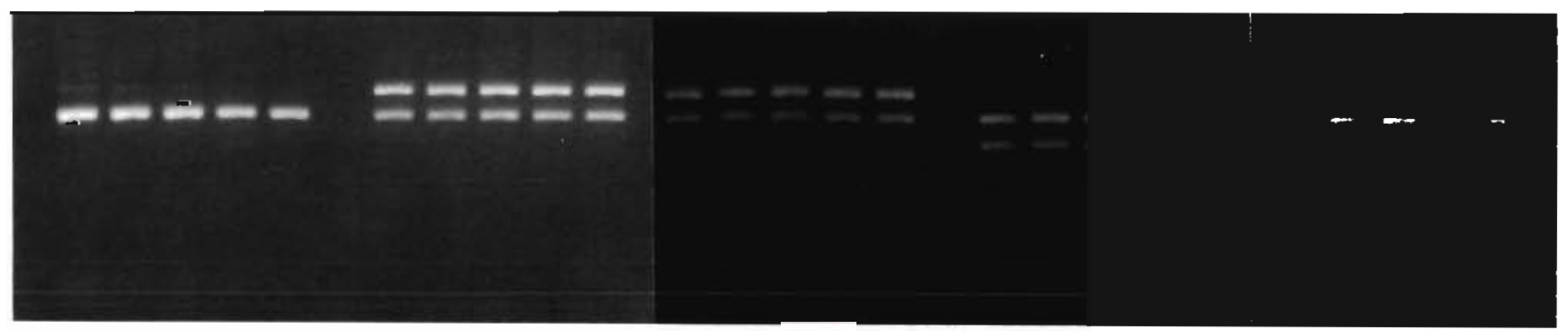

Fig. 5. Host species-specificity of zooxanthella ssRNA gene RFLPs. ssRNA genes were amplified using zooxanthella-specific PCR primers ss5Z and ss3Z from 5 distinct individuals of the following Hawaiian corals: (1 to 5) Montipora patula; (6 to 10) Montipora verrucosa; (11 to 15) Fungia (Pleuractis) scutaria; (16 to 20) Pocillopora damicornis; (21 to 25) Pocillopora meandrina. PCRamplification products were digested with TaqI and separated by agarose gel electrophoresis 
meandrina resembles a superposition of the $P$ damicornis and $M$. verrucosa RFLPs. When more PCR product is loaded, a small amount of the $M$. verrucosalike RFLP is apparent in the zooxanthellae from $P$. damicornis also (see Fig. 3, lane 13). Two ssRNA genotypes indicate either the presence of 2 kinds of algae, or a polymorphism within the multi-copy ssRNA genes of one alga.

\section{DISCUSSION}

Many marine organisms remain poorly understood because they have been difficult to identify and/or classify, often because they cannot be cultured. The present study and others (Rowan \& Powers 1991a, b) demonstrate how molecular genetic methods can be successfully applied to one difficult group, the zooxanthellae. Giovannoni et al. (1990) and Ward et al. (1990) are using similar methods to study natural populations of bacteria.

RFLP data (Figs. 3, $4 \&$ 5) and ssRNA sequences (Rowan \& Powers 1991a) show that different Symbiodinium-like zooxanthellae can be identified and classified using nuclear-encoded ssRNA genes. Because ssRNA evolves slowly (Appels \& Honeycutt 1986 , Sogin \& Gunderson 1987), 2 zooxanthella isolates with the same RFLP may not be the same alga: Symbiodinium microadriaticum and $S$. pilosum are clearly different organisms (Trench \& Blank 1987), but they are not distinguished by RFLPs (Fig. 4). Similarly, observing one zooxanthella RFLP in a host does not mean that the host contains only one type of alga. These limitations can be overcome by using PCR/RFLP methodology with more rapidly evolving DNA sequences. In any case, there is value in being able to distinguish organisms that are not similar: The first taxonomic decisions that biologists make are instinctively the higher ones. Hundreds of marine invertebrate species harbor zooxanthellae, and ssRNA gene RFLPs offer a rapid method for cataloguing these unknown algae.

The RFLP data in Fig. 3, 4 \& 5, as well as ssRNA sequences (Rowan \& Powers 1991b), suggest that there is more zooxanthella diversity between hosts than within hosts. This conclusion is qualified by the caveat that SSRNA RFLPs are not expected to measure diversity at lower taxonomic ranks: One host could contain a diverse collection of closely related (and therefore cryptic) algae. The conclusion remains, however, that more distantly related zooxanthellae (that do exhibit different ssRNA RFLPs) generally do not co-occur within a host species. In this sense zooxanthella diversity does appear to be greater between host species than within host species. Curiously, different zooxanthella RFLPs are not distributed along host taxonomic lines: One RFLP is common to a jellyfish (Cassiopeia frondosa), anemones (Aiptasia pulchella, Anthopleura xanthogrammica and $A$. elegantissima), a coral (Astrangia danae) and a gorgonian (Plexaura A); the scleractinian corals as a group contain 4 zooxanthella RFLPs; 4 zoanthids exhibit 3 zooxanthella RFLPs; etc. Zooxanthella ssRNA sequences support the conclusion that closely related zooxanthellae occur in distantly related hosts (Rowan \& Powers 1991b).

Different Symbiodinium 'strains' (reviewed by Trench 1987) or species (Trench \& Blank 1987) have previously been described from morphological, biochemical, physiological and behavioral observations of cultured zooxanthellae. Culturing zooxanthellae in vitro removed the confounding possibility of hostassociated phenotypic plasticity from these studies (Schoenberg \& Trench $1980 \mathrm{a}$, b) and also provided sufficient material for biochemical analyses (Blank et al. 1988, Blank \& Huss 1989). The present study contributes to this body of data. Different zooxanthella sSRNA RFLPs could reasonably be referred to as 'strains', especially where there is evidence of ecological or taxonomic specificity (Fig. 5). However, ssRNA sequences (Rowan \& Powers 1991a, b) indicate that some of these algae are less closely related than the epithet 'strain' would suggest. Informative taxonomic patterns exist with or without names.

Zooxanthella-specific PCR primers greatly simplified our study, but it should be noted that specificity introduces limitations. Primers ss $5 Z$ and ss $3 Z$ were designed according to ssRNA sequences from Symbiodinium microadriaticum and Symbiodinium $\# 8$, and known patterns of ssRNA sequence evolution (Sogin et al. 1986, Sogin \& Gunderson 1987) predict that these primers will also amplify genes from related algae. Some Symbiodinium algae, however, might have ssRNA genes with nucleotide substitutions that prevent primer function. There are ways around this problem. The dissimilarity between zooxanthellae and their hosts is great enough that specificity could be targeted to a broader group of dinoflagellates (Rowan \& Powers 1991a). This would make the exclusion of any zooxanthellae less likely. Secondly, zooxanthella-specific primers can be used singly, in combination with one universal primer. In this configuration only one or the other zooxanthella-specific primer needs to function, not both. Host sequences will not be amplified under these conditions because the PCR requires primers at both ends of the target molecule. The primer combination ss $5 / \mathrm{ss} 3 Z$ has been widely used with success in this manner (R.R. unpubl.).

PCR/RFLP methods require laboratory facilities that are not typically available near zooxanthella habitats. Because the PCR does not require high-quality DNA (Saiki 1990), preserving field samples for later analysis 
is not a problem. Zooxanthella lysates in DNAB with $1 \%$ SDS (see 'Methods and materials') can be prepared with minimal facilities (a centrifuge is optional since zooxanthella will sediment in $\mathrm{ZB}$ at $1 \mathrm{~g}$ ). For PCR purposes, these lysates are stable at room temperature. PCR-amplifiable zooxanthella DNA has been obtained from washed algae and from whole Anthopleura tentacles that were preserved in $50 \%$ ethanol (R.R. unpubl.). Samples kept in 10\% formalin have not been satisfactory. Desiccation is another option (Doyle \& Dickson 1987). Air-dried gorgonians, kept at ambient temperatures, are excellent sources of PCR-amplifiable zooxanthella DNA (R.R. unpubl.).

In conclusion, PCR methods are ideal for taxonomic and ecological studies of the genus Symbiodinium. The economy of studying freshly isolated zooxanthellae over cell cultures is enormous, and, because many attempts at zooxanthella culture are not successful (e.g. Schoenberg \& Trench 1980a), only natural isolates can provide a comprehensive assessment of zooxanthella diversity. Molecular genotypes are excellent data for phylogenetic analyses (reviewed by Hillis 1987, Nei 1987) that are especially appropriate for 'difficult' organisms like Symbiodinium (Rowan \& Powers 1991a, b). Symbiosis ecology, including questions of host or habitat (e.g. sun vs shade) specificity (Dustan 1979) and coral bleaching epidemics (Goreau 1964, Glynn 1983), will benefit from the ability to rapidly identify zooxanthella genotypes. As additional (more variable) zooxanthella genes are developed for PCR amplification, and as more symbioses are examined, we will obtain a more complete understanding of these fascinating and important organisms.

Acknowledgements. We thank R. K. Trench for cultured zooxanthellae, G. Muller-Parker for Aiptasia cultures, M. A. Coffroth for Plexaura A samples, and J. Mitton for collecting Psammogorgia. L. Brezinsky, C. Kanechika, and T. Humphrys generously provided facilities on Oahu, and we thank colleagues at the West Indies Laboratory and the national undersea Research Center for help on St. Croix. G. Muller-Parker. M. PowelI, G. J. Smith, and L. West contributed expertise and ideas. Supported by a NSF Postdoctoral Fellowship in Marine Biotechnology to R.R., and by a contract from the National Undersea Research Center, NOAA. Work in Woods Hole (with G. Muller-Parker) was carried out in conjunction with a summer course sponsored in part by the Office of Naval Research.

\section{LITERATURE CITED}

Appels, R., Honeycutt, R. L. (1986). rDNA: evolution over a billion years. In: Dutta, S. K. (ed.) DNA systematics. CRC Press, Boca Raton, p. 82-135

Blank, R. J., Huss, V A. R. (1989). DNA divergency and speciation in Symbiodinium (Dinophyceae) PI. Syst. Evol. 163: 153-163

Blank, R. J., Huss, V. A. R., Kersten, W. (1988). Base composi- tion of DNA from symbiotic dinoflagellates: a tool for phylogenetic classification. Arch. Microbiol. 149: 515-520

Blank, R. J., Trench, R. K. (1985). Speciation and symbiotic dinoflagellates. Science 229: 656-658

Blank, R. J., Trench, R. K. (1986). Nomenclature of endosymbiotic dinoflagellates. Taxon 35: 286-294

Dams, E., Hendricks, L., Van de Peer, Y., Neefs, J.-M., Smits, G., Vandenbempt, I., De Wachter, R. (1988). Compilation of small ribosomal subunit RNA sequences. Nucl. Acids Res. 16 (supplement): r87-r173

Doyle, J. J., Dickson, E. E. (1987). Preservation of plant samples for DNA restriction endonuclease analysis. Taxon 36: $715-722$

Dustan, P. (1979). Distribution of zooxanthellae and photosynthetic chloroplast pigment of the reef building coral Montastrea annularis Ellis and Solander in relation to depth on a West Indian coral reef. Bull. mar. Sci. 29: 79-95

Freudenthal, H. D. (1962). Symbiodinium gen. nov. and Symbiodinium microadriaticum sp. nov, a zooxanthella: taxonomy, life cycle, and morphology. J. Protozool 9: 45-52

Giovannoni, S. J., Britschgi, T B., Moyer, C. L., Field, K. G. (1990). Genetic diversity in Sargasso Sea bacterioplankton. Nature, Lond. 345: 60-63

Glynn, P. W. (1983). Extensive 'bleaching' and death of reef corals on the Pacific coast of Panama. Environ. Conserv. 10: $149-154$

Goreau, T. F. (1964). Mass expulsion of zooxanthellae from Jamaican reef communities after hurricane Flora. Science 145: 383-386.

Goreau, T. F., Goreau, N. I. (1959). The physiology of skeleton formation in corals. II. Calcium deposition by the hermatypic corals under various conditions in the reef. Biol. Bull. mar. biol. Lab., Woods Hole 117: 239-250

Hillis, D. M. (1987). Molecular vs. morphological approaches to systematics. Ann. Rev. Ecol. Syst. 18, 23-42

Innis, M. A., Gelfand, D. H., Sninsky, J. J., White, T. J. (1990). PCR protocols. A guide to methods and applications. Academic Press, New York

Kevin, M. J., Hall, W T., McLaughlin, J. J. A., Zahl, P. A. (1969). Symbiodinium microadriaticum Freudenthal, a revised taxonomic description, ultrastructure. J. Phycol. 5: 341-350

Maragos, J. E. (1977). Order Scleractinia. In: Devaney, D. M., Eldredge, L. G. (eds.) Reef and shore fauna of Hawaii. Bishop Museum Press, Honolulu, p. 158-241

McLaughlin, J. J. A., Zahl, P. A. (1966). Endozoic algae. In: Henry, S. M. (ed.) Symbiosis, Vol I. Academic Press, New York, p. 257-297

Medlin, L., Elwood, H. J., Stickel, S., Sogin, M. L. (1988). The characterization of enzymatically amplified eukaryotic 16S-like rRNA-coding regions. Gene 71: 491-499

Muscatine, L., Porter, J. W. (1977). Reef corals: mutualistic symbioses adapted to nutrient-poor environments. Bioscience 27: 454-460

Nei, M. (1987) Molecular evolutionary genetics. Columbia University Press, New York

Rowan, R., Powers, D. A. (1991a). Ribosomal RNA sequences and the diversity of symbiotic dinoflagellates (zooxanthellae). Proc. natn. Acad. Sci. USA (in press)

Rowan, R., Powers, D. A. (1991b). A molecular genetic classification of zooxanthellae and the evolution of animal-algal symbioses. Science (in press)

Saiki, R. K. (1990). Amplification of genomic DNA. In: Innis, M. A., Gelfand, D. H., Sninsky, J. J., White, T. J. (eds.) PCR protocols. A guide to methods and applications. Academic Press, New York, p. 13-20

Saiki, R. K., Gelfand, D. H., Stoffel, S., Scharf, S. J., Higuchi, R., Horn, G. T., Mullis, K. B., Erlich, H. A. (1988). Primer- 
directed enzymatic amplification of DNA with a thermostable DNA polymerase. Science 239: 487-491

Schoenberg, D. A., Trench, R. K. (1980a). Genetic variation in Symbiodinium (= Gymnodinium) microadriaticum Freudenthal, and specificity in its symbiosis with marine invertebrates. I. Isoenzyme and soluble protein patterns of axenic cultures of $S$. microadriaticum. Proc. R. Soc. Lond. (B) 207: 405-427

Schoenberg, D. A., Trench, R. K. (1980b). Genetic variation in Symbiodinium (= Gymnodinium) microadriaticum Freudenthal, and specificity in its symbiosis with marine invertebrates. II. Morphological variation in S. microadriaticum. Proc. R. Soc. Lond. (B) 207: 429-444

Sogin, M. L. (1990). Amplification of ribosomal RNA genes for molecular evolution studies. In: Innis, M. A., Gelfand, D. H., Sninsky, J. J., White, T. J. (eds.) PCR protocols. A guide to methods and applications. Academic Press, New York, p. $307-314$

Sogin, M. L., Elwood, H. J., Gunderson, J. H. (1986). Evolutionary diversity of eukaryotic small-subunit rRNA genes. Proc. natn. Acad. Sci. USA 83: 1383-1387

Sogin, M. L., Gunderson, J. H. (1987). Structural diversity of eukaryotic small subunit ribosomal RNAs. Ann. N.Y. Acad. Sci. 503: 125-139

This article was submitted to the editor
Taylor, D. L. (1969). Identity of zooxanthellae isolated from some Pacific Tridacnidae. J. Phycol. 5: 336-340

Taylor, D. L. (1974). Symbiotic marine algae: taxonomy and biological fitness. In: Vernberg, W. B. (ed.) Symbiosis in the sea. Univ. of South Carolina Press, Columbia, p. 245-262

Trench, R. K. (1987). Dinoflagellates in non-parasitic symbioses. In: Taylor, F. J. R. (ed.) The biology of dinoflagellates. Blackwell Scientific, Oxford, p. 530-570

Trench, R. K., Blank, R. J. (1987). Symbiodinium microadriaticum Freudenthal, $S$. goreauii sp. nov., S. kawagutii sp. nov. and $S$. pilosum sp. nov.: gymnodinioid dinoflagellate symbionts of marine invertebrates. J. Phycol. 23: 469-481

Ward, D. M., Weller, R. Bateson, M. M (1990). 16S rRNA sequences reveal numerous uncultured microorganisms in a natural community. Nature, Lond. 345: 63-65

Wu, D. Y., Ugozzoli, L., Pal, B. K., Wallace, R. B. (1989). Allelespecific amplification of Beta-globin genomic DNA for diagnosis of sickle cell anemia. Proc natn. Acad. Sci. USA 86: $2757-2760$

Yanisch-Perron, C., Vieira, J., Messing, J. (1985). Improved M13 phage cloning vectors and host strains: nucleotide sequences of the M13mp18 and pUC19 vectors. Gene 33: $103-119$

Manuscript first received: August 21, 1990

Revised version accepted: January 11, 1991 